\title{
Gerbode's defect associated with acute sinus node dysfunction as a complication of infective endocarditis
}

\author{
C Michel, M A Rabinovitch, T Huynh
}

The Montreal General Hospital, McGill

University, Division of Cardiology, Montreal, Quebec, Canada C Michel

M Rabinovitch

T Huynh

Correspondence to:

Dr M A Rabinovitch, Montreal General Hospital,

Room E5-200, 1650 Cedar Avenue, Montreal, Quebec, Canada H3G 1A4.

Accepted for publication 2 January 1996 Division of Cardiology,

\begin{abstract}
A 52 year old man with long-standing moderate aortic insufficiency who was taking clonidine for hypertension presented with a three week history of fever, chills, and malaise. His III/VI diastolic decrescendo murmur was unaltered from previous examinations. The admission transthoracic Doppler echocardiogram (TTE) showed an eccentric jet of moderate aortic regurgitation directed toward the interventricular septum. Blood cultures grew streptococcus viridans. After two weeks of treatment with antibiotics a new III/VI blowing systolic murmur was auscultated maximally at the left sternal border in the third and fourth intercostal spaces.

Asymptomatic sinus pauses of up to 4-5 seconds were also noted at this time. A repeat TTE showed a new systolic jet from the left ventricular outflow tract just below the aortic valve to the right atrium. A transoesophageal echocardiogram confirmed this finding (figure). The peak jet velocity was $3-4 \mathrm{~m} / \mathrm{s}$, consistent with a restrictive defect. The sinus
\end{abstract}

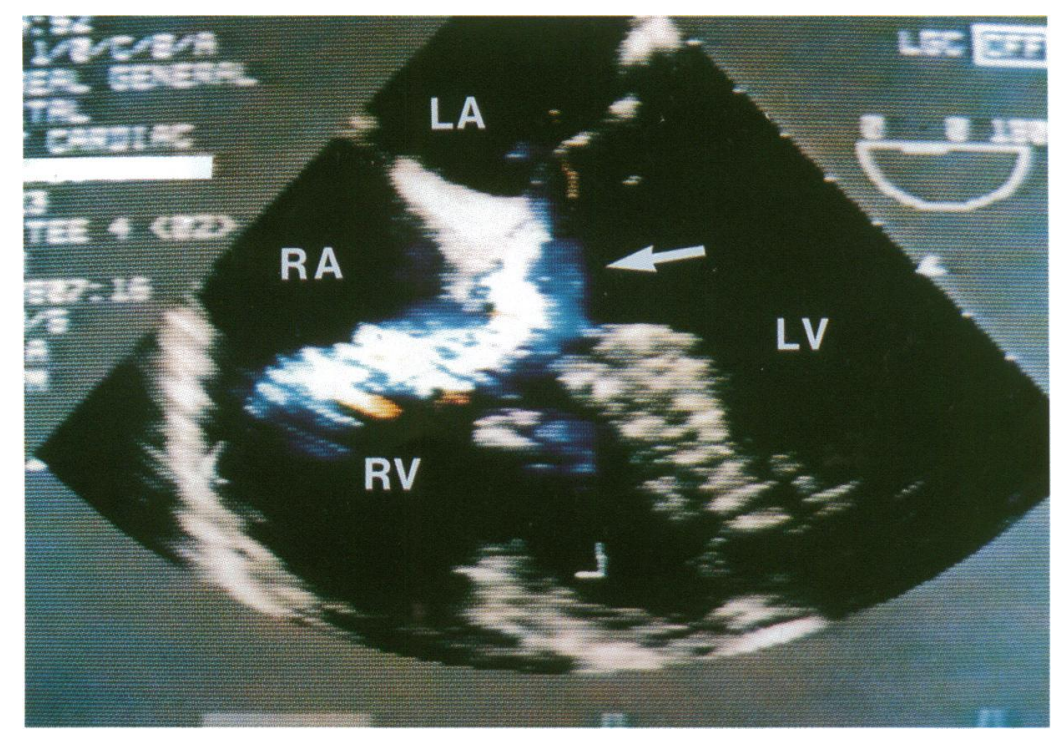

Transoesophageal echocardiogram showing turbulent flow between the left ventricle and right atrium. $L V$, left ventricle; $R V$, right ventricle; $L A$, left atrium; $R A$, right atrium. pauses shortened to under 2 seconds after he stopped taking clonidine. The patient was discharged after two further weeks of treatment with antibiotics.

Though a valve vegetation was never seen on the echocardiograms, it is quite likely that the patient developed infective endocarditis on the incompetent aortic valve with subsequent metastatic infection and perforation of the upper part of the membranous septum. ${ }^{1}$ This could have caused the relatively small shunt between the left ventricle and right atrium.

Left ventricular to right atrial congenital defects were characterised by Gerbode in his description of their surgical management in children. ${ }^{2}$ The more common type originates in the interventricular membranous septum and forms a communication between the left ventricle and the right atrium through a defect in the septal leaflet of the tricuspid valve. In the less common form, a hole in the atrioventricular membranous septum (above the tricuspid valve) leads to direct communication between the left ventricle and right atrium with an intact tricuspid valve.

Gerbode's defect, as it subsequently became known, has rarely been documented as an acquired lesion in association with infective endocarditis. ${ }^{3-6}$ In our case, acute stretching of the right atrium by the shunt could have exacerbated pre-existing sinus node dysfunction in a patient taking clonidine.

1 Kaye D. Endocarditis. New York: Raven Press, 1992; 191-200.

2 Gerbode F. Syndrome of left ventricular-right atrial shunt: successful surgical repair of defect in five cases with observation of bradycardia on closure. Ann Surg 1958;148:433-46.

3 Cantor $S$. Left ventricular-right atrial shunt due to bacterial endocarditis. Chest 1971;60:552-4.

4 Battin M, Fong LV, Monro JL. Gerbode ventricular septal defect following endocarditis. Eur $\mathcal{F}$ Cardiothorac Surg 1991;5:613-4.

5 Elian D, Segni ED, Kaplinsky E, Mohr R, Vered Z. Acquired left ventricular-right atrial communication caused by infective endocarditis detected by transesophageal echocardiography: case report and review of the literature. $₹ \mathrm{Am}$ Soc Echocardiogr, 1995;8:108-10.

6 Winslow TM, Friar DA, Larson AW, Barry MJ. A rare inslow TM, Friar DA, Larson AW, Barry MJ. A rare
complication of aortic valve endocarditis: diagnosis with transesophageal echocardiography. $\mathcal{F} \mathrm{Am}$ Soc Echocardiogr 1995;8:546-8. 